\title{
Can a polycentric structure affect travel behaviour? A comparison of Melbourne, Australia and Riyadh, Saudi Arabia
}

\author{
M. Alqhatani $\cdot$ S. Setunge $\cdot$ S. Mirodpour
}

Received: 26 November 2013/Revised: 17 May 2014/ Accepted: 19 May 2014/Published online: 7 August 2014

(C) The Author(s) 2014. This article is published with open access at Springerlink.com

\begin{abstract}
This study models the impact of the shift from a monocentric private-car-oriented city to polycentric public-transport-oriented city. Metropolitan areas have suffered traffic problems-in particular increase in travel time and travel distance. Urban expansion, population growth and road network development have led to urban sprawl in monocentric cities. In many monocentric cities, travel time and distance has steadily increased and is only expected to increase in the future. Excessive travel leads to several problems such as air pollution, noise, congestion, reduction in productive time, greenhouse emissions, and increased stress and accident rates. This study examines the interaction of land use and travel. A model was developed and calibrated to Melbourne and Riyadh conditions and used for scenario analysis. This model included two parts: a spatial model and a transport model. The scenario analysis included variations of residential and activity distribution, as well as conditions of public transport service.
\end{abstract}

Keywords Monocentric - Polycentric - Private mode · Public transport · Four-step transport modelling

\section{Introduction}

Since the end of World War II, economic growth and advancement in transport technologies have resulted in

M. Alqhatani $(\bowtie) \cdot$ S. Mirodpour

School of Civil, Environmental and Chemical Engineering,

RMIT University, GPO Box 2476, Melbourne, VIC 3001,

Australia

e-mail: mohammed.alqhatani@student.rmit.edu.au

S. Setunge

Ministry of Higher Education, Riyadh, Saudi Arabia rapid urbanisation. This rapid urbanisation has promoted the shift from compact monocentric city to urban sprawl which has caused not only traffic congestion problems, but also longer trip distances, increased trip times and traffic accidents [1].

Many researchers have suggested that monocentric urban structures fail to optimise existing transport network utilisation. CBD workers arrive at similar times each day generating an inward commuting flow from the outer suburbs during morning peak hours and an outward commuting flow during evening peak hours [2]. Decentralisation of employment can be made possible by re-organisation of the suburban structure, by shifting from single core city centre to multiple suburban activity centres (employment, shopping, recreation, etc.) located in the periphery of the city.

These suburban activity centres become strong alternatives to the CBD, potentially combining the advantage of sprawl locations (low density, lower land price and less traffic congestion) with the advantages of subcentre locations (economy, urbanisation and personal interaction) which are connected by a good transport system [3, 4].

In Australia, there is much interest in encouraging a change in urban structure because it delivers significant transport improvements, particularly public transport. All major cities in Australia have developed spatial plans that encourage transit-oriented development and in-fill development (the so-called 'urban consolidation') [2].

These transport and land use policies look to bring residences closer to public transport and to key activity centres, in an attempt to improve public transport share and to respond to concerns about traffic congestion [5]. However, there are other approaches towards the mix of activity transport and land use, and interest in employment decentralisation has been encouraged in Melbourne and Riyadh by the future master plan 2030 . 
In Melbourne, activity centres were identified and classified into the following categories: 25 principal activity centres, 79 major activity centres and 10 specialised activity centres [6]. The latest focus advocates a polycentric city with new six subcentres in addition to the CBD areas, called Central Activity Districts, such as Box Hill, Broadmeadows, Footscray, Frankston and Ringwood [7]. In contrast, Riyadh's land use and transport polices have adopted a polycentric model, identifying six subcentres with traditional centres in the future master plan 2030 [8].

While the benefits of polycentric urban structure over monocentric urban structure have been well examined and qualitatively reported on in the literature, examination of the shift from monocentric to polycentric urban structure and quantification of its effects on travel remain a key gap in the existing literature on this topic. This study endeavours to discover how this shift reduces travel.

In conjunction with changes to urban structure, public transport has been proposed as a key solution that can decrease congestion and trip length, and urban form (population and employment distribution) is recognised as a useful way to reduce trip length. Some cities, such as Riyadh, have so far limited public transport service. However, Riyadh is also proposing to restructure to a polycentric city. It is, therefore, useful to examine the significance of a public transport system for a polycentric structure urban policy.

Riyadh and Melbourne have been selected as case studies. Riyadh and Melbourne are similar in urban form and population number, yet different in transport systems. Private mode is predominantly used in Riyadh and Melbourne. However, Melbourne has a good public transport system while Riyadh is constrained by the limited scale of its public transport network.

The objective of this paper is to quantify the impact of polycentric urban structure policy in Melbourne and Riyadh, as well as the significance of public transport in supporting the polycentric urban structure.

\section{Literature review}

It has been understood that monocentric employment structures lead to long travel times for commuters, as well as strong flows in one direction. Concentration of flows into a small area creates traffic congestion for all modes during peak times. On the other hand, polycentric structures are linked to decreased travel times and distance, through a better mix and balance of employment and residential areas [2].

\subsection{Polycentric structure examples}

In cities of Australia and New Zealand, residential dispersion has occurred but this has not led to a similar form of employment dispersion. This is partly due to the development of white-collar office jobs, as seen in the Melbourne CBD, where between 1996 and 2006 100,000 new white-collar jobs were created (Mees et al. [10]).

The overcentralisation of office employment in Australian CBD areas has been linked to significant levels of long travel distance and commuting time, traffic congestion, poor balance between employment-housing structures, significant levels of subsidy for public transport and excessive costs for office leases. Urban traffic congestion has grown significantly, and is recognised as a key policy area and optimal growth and decentralisation policies have been proposed as a response to these issues [2].

Review of research into employment decentralisation policies and effect on transport has been developed [2]. Transport outcomes are different in different cities, with decentralisation to rail-based localities in Japan and Singapore being extremely successful in decreasing traffic congestion and increasing the performance of transit systems. Additionally, decentralisation in London over the 1960s-1970s has also decreased traveller flows into the CBD.

In New South Wales (NSW), the government has promoted a secondary centre in Parramatta. Parramatta started with 10,000 jobs in 1971 and reached 40,000 jobs by 2005, and Parramatta contributed to reduction in travel time. In a recent master plan, the NSW government (City of Cities) proposed to strengthen two new regional subcentres which are Liverpool and Penrith [2].

However, in San Francisco, employment decentralisation has had little impact on reduction of mean distances or travel times for commuters, with a lack of development of self-containment. Within Stockholm, the development of urban fringe residential areas for workers has led to increased mean commuting distances, and ultimately led to higher staff turnover [2].

While there appears to be positive outcomes to decentralisation, there have been negative outcomes as well. Little is known about how long it takes workers and households to transition to new spatial arrangements after a workplace relocation, say, by moving house, changing to a job located elsewhere or changing schools for children. There is a risk that decentralisation can lead to higher proportion of suburb-to-suburb commutes which may entail increases in car use as more workers travel farther [9].

\subsection{Polycentric structure of Melbourne and Riyadh}

The polycentric urban structure policy of Melbourne and Riyadh need to be better understood based on the specific context of these two cities. Most of the studies conducted for Melbourne and Riyadh have been qualitative rather than quantitative studies. In Melbourne, the Department of 
Planning and Community Development [11] mentioned that shifting from one main centre to more alternative centres has a similar CBD area function, which will reduce congestion and allow residents to spend less time travelling to and from work. Meanwhile, in Riyadh, the Arriyadh Development Authority (ADA) [8] mentioned that 'subcentres will create the opportunity for a balance between work and residence in the new growth sectors of city suburbs. The sub-centres will have significant effects to the pattern of the daily trips between the suburbs and the city centre by creating new workplaces. This also will reduce the total of number daily trip, because may residents will be living and working in the same section of the city and therefore the movement will be directed away from the city centre area, instead to the current pattern of going to the city centre. There has been no clear view about how this shift's dynamic process works.

This study aims to contribute to the better understanding of the impact of polycentric structure. A model analysis was conducted to quantify the impact of the shift from monocentric structure to polycentric structure in Melbourne and Riyadh. The analysis focusses on the impact of variants in activity and residential redistribution as shown in Fig. 1.

\section{Methodology}

\subsection{Data collection}

One of the major tasks in this study was to collect data used to develop a land use/transport model. Data collection was divided into two groups: land use and demographic information, and transport data. In Riyadh, the demographic and population data were collected by the Municipality of Riyadh (MOR) in 2008; however, the land use data were conducted by the ADA in 2002 .

In Melbourne, the demographic and population data were collected by the Department of Transport of Victoria in 2008; however, the land use data were collected by the Local Municipalities Councils (2009).

The explanatory variables applied to the model are based on data availability. The variables were formed in relation to the socioeconomic characteristics of households, demographic data, land use and urban form. The data for Riyadh were sourced from the 2008 survey dataset, created by the MOR; and for Melbourne the data were sourced from the Department of Transport (DOT), Melbourne, Victoria. The data were within the city's Traffic Analysis Zones (TAZs), with Riyadh featuring 2,166 TAZs and Melbourne having 2,253 TAZs.

Riyadh's trip data were obtained from the 2008 MOR report, while for Melbourne they were sourced from the 2008 DOT data. The data focused on trip purposes, including home-based work (HBW); home-based education including primary, secondary and high school; homebased recreation; home-based shopping; home-based other; and non-home based.

The origin and destination (OD) trip data for Riyadh were also sourced from MOR (2008) and for Melbourne they were similarly sourced from DOT (2008). Trip data are available for the AM peak period ( $2 \mathrm{~h})$ in Riyadh, this period was measured across $2 \mathrm{~h}$ in Melbourne, and the OD trip matrix was organised by car, public transport and walking modes. Trip distance is calculated as the shortest distance between two centroid points which were sourced

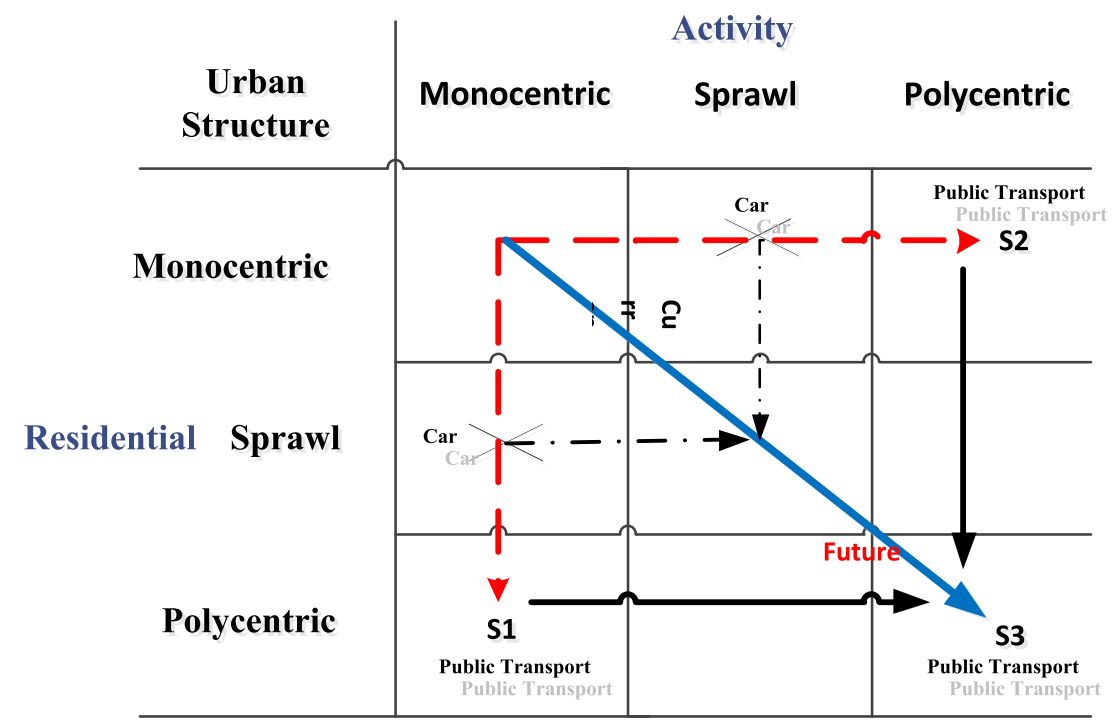

Fig. 1 Urban structure and population distribution scenarios process 
by MOR and DOT in 2008 in Riyadh and Melbourne, respectively.

At present, Riyadh has no tram and train service but it has been designed to be used in the upcoming years. Public transport data have been collected from MOR (2008). Also, the data of walk trip distance were extracted from Koushki's study (1989) and used to predict the walk trip mode share in Riyadh.

Socioeconomic data for Melbourne were applied at the TAZ level and used as an independent variable of the models in this study, and the socioeconomic variables included the number of employed residents, the number of households, age group (0-17, 18-64, and 65+), the number of jobs and the number of students.

Finally, land use data were also applied as an independent variable, with independent variables organised into two categories. Firstly, socioeconomic variables and land use variables were broken into building gross floor area (GFA), and secondly the number of buildings and activities in each zone was measured. The GFA for Riyadh was sourced from the ADA (2002), and for Melbourne it was sourced from the Local Municipalities Councils (2009). The number of buildings and activities in each zone measured the amount of retail, shopping areas and universities, with the last measure providing strong analysis for trip attraction in Riyadh. Land use data for Melbourne were not readily available for this study and were not used.

\subsection{Land use/transport interaction (LUTI) modelling}

This section describes the land use model and transport model used in the analysis.

\subsubsection{Land use model}

The land use model is a spatial model which is based on several input variables such as population, employment, housing and businesses. The interaction of spatial settlement is created by the attractiveness of the spatial cells. The interaction between the spatial model and the transport network can be calculated by the accessibility indices, which describe accessibility of different regions in the city, in turn representing access to employment, shopping and recreational facilities. Geographic Information System was used for this purpose.

\subsubsection{Transport model}

A four-step transport model which models trip generation, distribution, choice of mode and traffic assignment was used to model transport network performance (Fig. 2).

The first module is trip generation, which makes use of land use and socioeconomic data, such as demographic and population data, to determine the number of trips produced by and attracted to traffic zones. The second module is trip distribution which determines the OD of trips that have been estimated in the first module. The third module, model split, organises the trip into different modes of transport (i.e. private mode, train, tram, bus, cycling and walking). The fourth module is traffic assignment which allocates trips to different modes in the transportation network [12]. This study did not involve traffic assignment due to limitations in resources and data. Base year travel time and cost estimates were assumed in this study.

\subsubsection{Model calibration and validation}

The model calibration process refers to an estimate of the model parameters to fit the model results to a set of observed data, while the validation process refers to an evaluation of the results of the model outputs using the calibrated model parameters compared to the observed outcomes. In this study, part of the land use transport datasets were used for calibration and the remainder for validation. The data were divided into two groups: $80 \%$ for calibration and $20 \%$ for validation by applying cross-classification method because past data for both the cities were unavailable.

In Melbourne, the following Table 1 compares Trips, VKT and mode share estimated by the model and estimated based on the available data. The model was moderately accurate. The model was considered adequate for the purpose of this study given the resources available. In the case of Riyadh meanly all trips are made by cars with limited PT services at that amount. In the future PT will be improved and some trips will use PT.

Figures 3, 4 and 5 show the trip length distribution based on the model and available data.

\subsubsection{Model application}

The model was then applied to scenario analysis. This analysis examined both future HBW and NHBW trips. The explanatory variables for HBW and NHBW for Melbourne and Riyadh are as follows (Table 2).

Four scenarios were set for the scale and distribution activity and residential areas, as follows (Fig. 6):

Scenario 0 exhibits monocentric structure (existing structure) without change in structure and network.

Scenarios 1, 2 and 3 exhibit polycentric structures with variations in the redistribution of employment and residences, as follows:

- Scenario 1 has 5 new subcentres with redistribution of population around the new subcentres.

- Scenario 2 has 5 new subcentres with redistribution of employment around the new subcentres. 


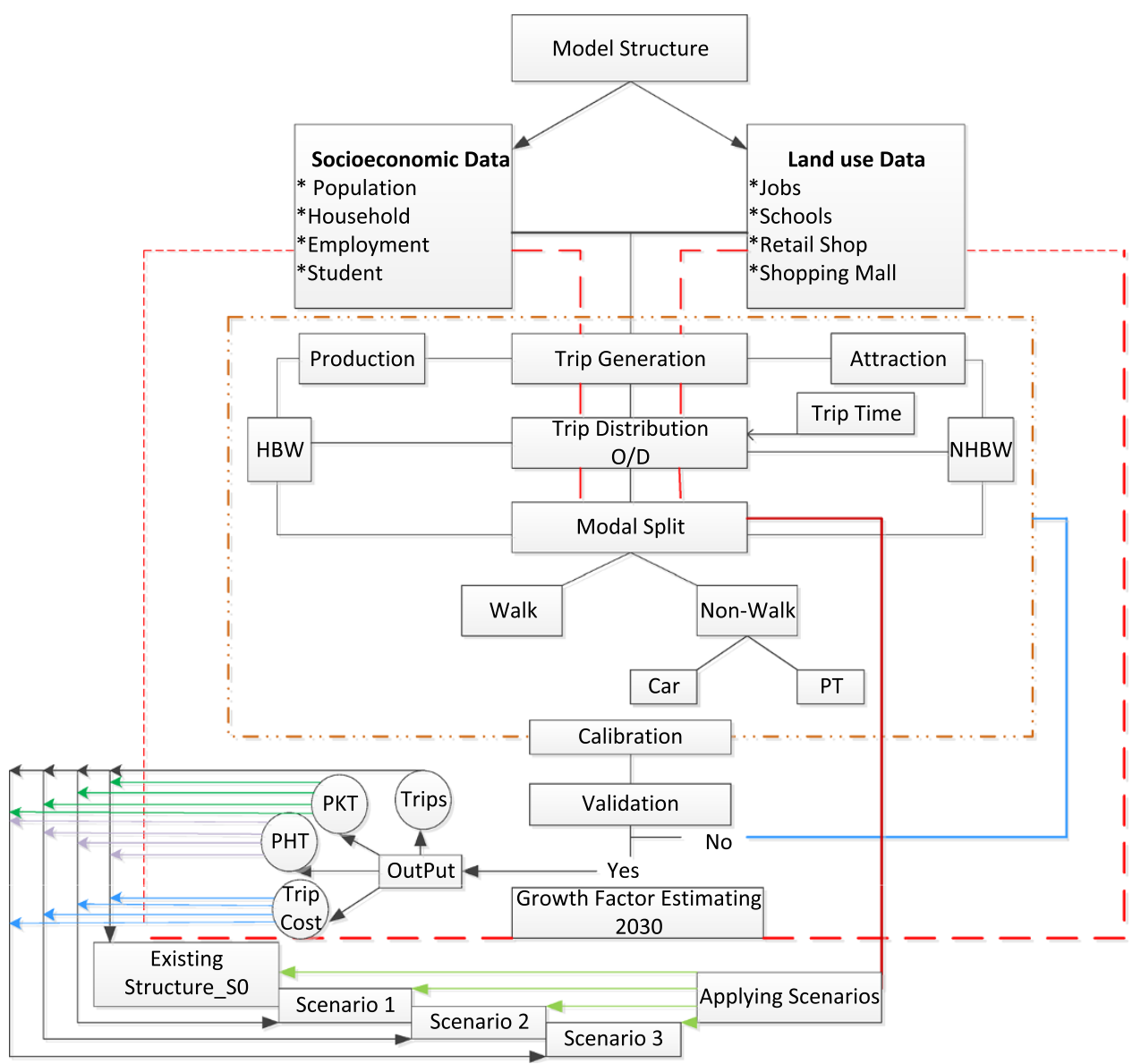

Fig. 2 Land use and transport model interaction process

Table 1 The comparison of VKT and mode share between observed data and model

\begin{tabular}{lll}
\hline Indicator & \multicolumn{2}{l}{ Melbourne model } \\
\cline { 2 - 3 } & Estimated from available data & Estimated by model \\
\hline VKT & $25,530,322$ & $30,075,288$ \\
Mode share & & \\
Car & $1,996,470$ & $1,769,266$ \\
Transit & 270,884 & 493,184 \\
Walk & 171,469 & 171,911 \\
\hline
\end{tabular}

- Scenario 3 has 5 new subcentres with redistribution of both population and employment around the new subcentres (see Fig. 2).

Additionally, different transport network structures and their impact on the traffic congestion, as well as spatial fragmentation, and trip times and distances were analysed.

Scenario 0 is paternal after historical growth from 2008 year conditions, while Scenarios 1, 2 and 3 were formulated based on varying redistribution patterns. The base year was set as 2008 and the future analysis year was set as

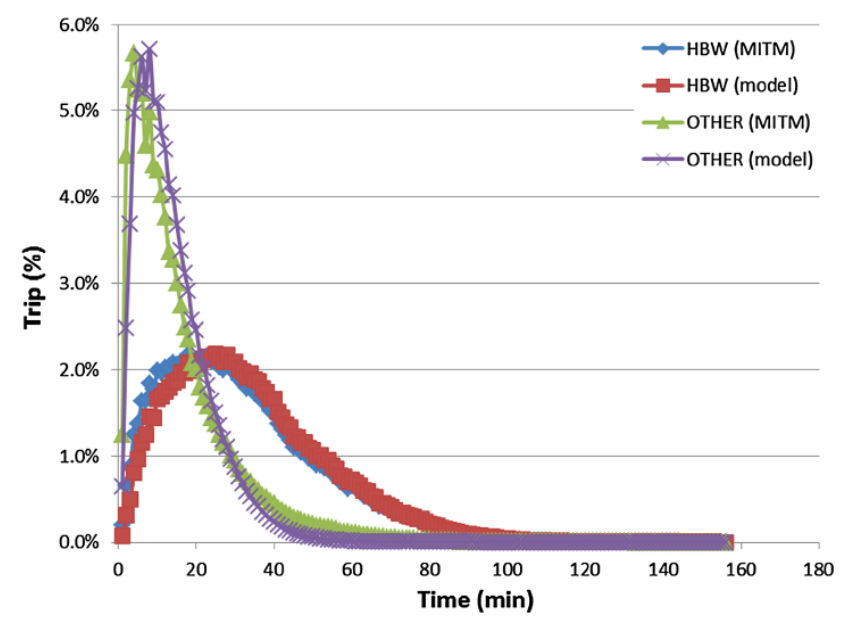

Fig. 3 Distribution of trip length in Melbourne between the model and observed data

2030. For redistributing activity or residence, it was assumed that $7.5 \%$ at the incremental in activity/residence will add to the CBD, while the remaining $92.5 \%$ will be shared amongst the new subcentres. The area outside the $\mathrm{CBD}$ or subcentres will remain as 2008 (see Tables 3 and 4). 


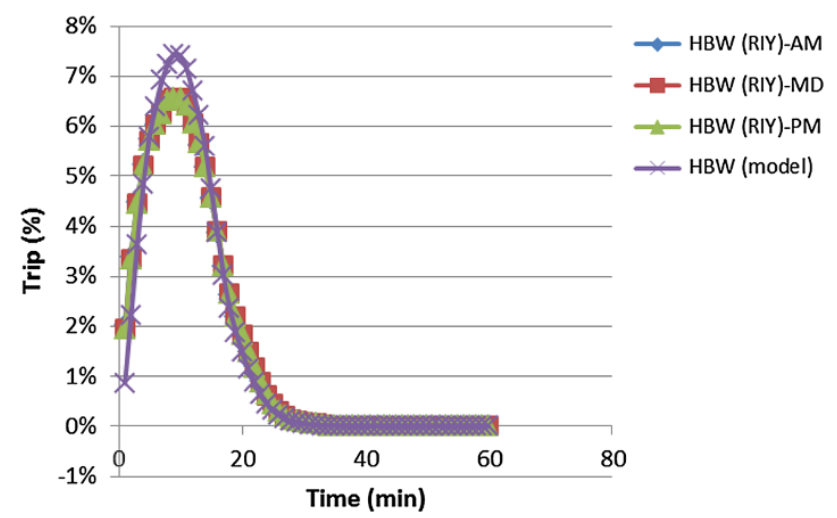

Fig. 4 Distribution of HBW trip length in Riyadh between the model and observed data

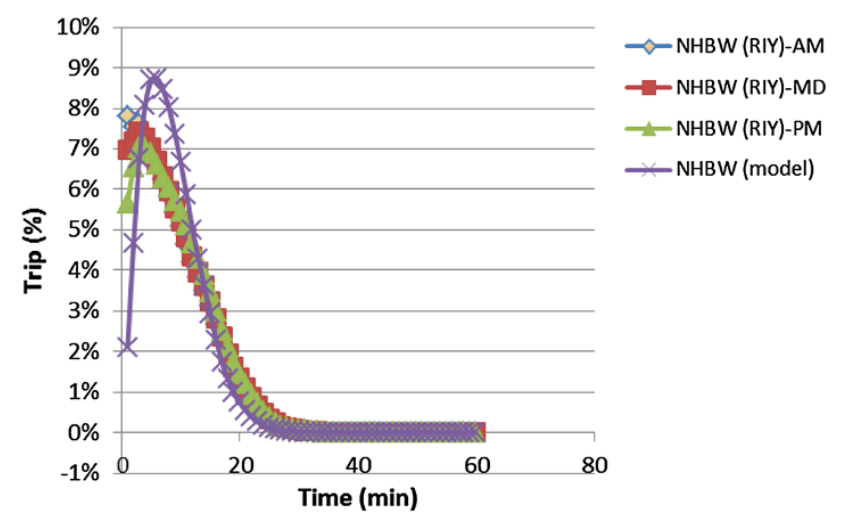

Fig. 5 Distribution of NHBW trip length in Riyadh between the model and observed data

Table 2 The explanatory variables which are used for Melbourne and Riyadh

\begin{tabular}{lll}
\hline $\begin{array}{l}\text { Trip } \\
\text { purpose }\end{array}$ & $\begin{array}{l}\text { Explanatory variables for } \\
\text { Melbourne }\end{array}$ & $\begin{array}{l}\text { Explanatory variables for } \\
\text { Riyadh }\end{array}$ \\
\hline HBW & Number of workers & Number of workers \\
& Number of households & Number of households \\
& Number of jobs & Number of jobs \\
NHBW & Number of workers & Number of workers \\
& Number of households & Number of households \\
& Number of student & Number of student \\
& Number of jobs & Number of jobs \\
& Number of students in & Number of students in school \\
& school & Number of retail shops \\
& Number of retail shops & Number of malls \\
& & Number of Students in \\
& & Universities \\
\hline
\end{tabular}

The growth in total population or activity was based on historical trends as sourced from ADA in Riyadh and the Australia Bureau of Statistics in Melbourne.

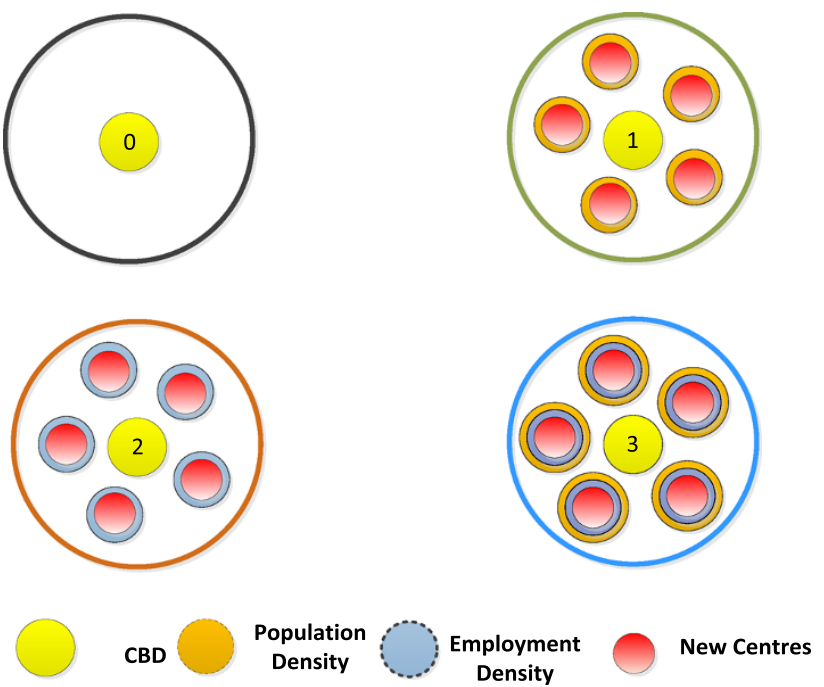

Fig. 6 Four scenarios in different structures

\section{Model result}

The comparative modelling suggests significant changes in travel behaviour under idealised decentralisation scenarios in both Riyadh and Melbourne.

\subsection{Trip rates}

\subsubsection{HBW purpose}

In Melbourne, car trip rates declined in scenarios 1 and 3, and not in scenario 2. PT trip rates decreased in scenarios 2 and 3; however, it increased in scenario 1 . Walk trip rates increased in scenarios 1 and 3, yet there was a slight decrease in scenario 2 (Table 5).

In Riyadh, car trip rates declined in all scenarios. Scenario 3 decreased to a greater degree compared to scenarios 1 and 2. PT trip rates increased in scenarios 1, 2 and 3. Walk trip rates increased in all scenarios. Scenario 3 had the highest walk trip rates compared to all scenarios (Table 6).

\subsubsection{NHBW purpose}

In Melbourne, car trip rates declined in all scenarios. PT trip rates declined in scenario 2 , and increased slightly in scenarios 1 and 3. Walk trip rates increased in all scenarios (Table 5).

In Riyadh, car trip rates declined in all scenarios. PT trip rates declined in scenarios 2 and 3, and increased slightly in scenario 1. Walk trip rates increased in all scenarios; scenario 3 had the highest walk trip rate (Table 6). 
Table 3 The distribution of residential and activities into six centres by different scenarios in Riyadh

\begin{tabular}{|c|c|c|c|c|c|c|c|}
\hline Factors & Variables & Centre & 2008 & 2030 (Scenario 0) & Scenario 12030 & Scenario 22030 & Scenario 32030 \\
\hline \multirow[t]{24}{*}{ Residential } & \multirow[t]{8}{*}{ Households } & CBD & 2,096 & 2,351 & 250,837 & 2,351 & 250,837 \\
\hline & & 1 & 1,744 & 78,513 & 506,069 & 78,513 & 506,069 \\
\hline & & 2 & 3,089 & 225,178 & 507,414 & 225,178 & 506,069 \\
\hline & & 3 & 2,268 & 43,460 & 506,593 & 43,460 & 506,593 \\
\hline & & 4 & 917 & 22,825 & 505,242 & 22,825 & 505,242 \\
\hline & & 5 & 2,507 & 22,451 & 506,832 & 22,451 & 506,832 \\
\hline & & Other & 763,055 & $3,151,264$ & 763,055 & $3,151,264$ & 763,055 \\
\hline & & Total & 775,676 & $3,546,042$ & $3,546,042$ & $3,546,042$ & $3,546,042$ \\
\hline & \multirow[t]{8}{*}{ Workers } & CBD & 4,884 & 5,478 & 584,701 & 5,478 & 584,701 \\
\hline & & 1 & 4,070 & 183,181 & $1,179,653$ & 183,181 & $1,179,653$ \\
\hline & & 2 & 7,207 & 525,360 & $1,182,790$ & 525,360 & $1,182,790$ \\
\hline & & 3 & 5,290 & 101,379 & $1,180,873$ & 101,379 & $1,180,873$ \\
\hline & & 4 & 2,143 & 53,342 & $1,177,726$ & 53,342 & $1,177,726$ \\
\hline & & 5 & 5,846 & 52,347 & $1,181,429$ & 52,347 & $1,181,429$ \\
\hline & & Other & $1,779,119$ & $7,345,202$ & $1,779,119$ & $7,345,202$ & $1,779,119$ \\
\hline & & Total & $1,808,559$ & $8,266,288$ & $8,266,288$ & $8,266,288$ & $8,266,288$ \\
\hline & \multirow[t]{8}{*}{ Students in residences } & CBD & 2,960 & 3,320 & 384,874 & 3,320 & 384,874 \\
\hline & & 1 & 3,459 & 155,681 & 778,753 & 155,681 & 778,753 \\
\hline & & 2 & 2,457 & 179,105 & 777,751 & 179,105 & 777,751 \\
\hline & & 3 & 1,663 & 31,870 & 776,957 & 31,870 & 776,957 \\
\hline & & 4 & 903 & 22,477 & 776,197 & 22,477 & 776,197 \\
\hline & & 5 & 5,945 & 53,233 & 781,239 & 53,233 & 781,239 \\
\hline & & Other & $1,782,550$ & $6,803,567$ & $6,803,567$ & $1,782,550$ & $1,782,550$ \\
\hline & & Total & $1,808,387$ & $7,401,914$ & $7,401,914$ & $7,401,914$ & $7,401,914$ \\
\hline \multirow[t]{24}{*}{ Activities } & \multirow[t]{8}{*}{ Jobs } & CBD & 4,830 & 5,417 & 5,417 & 507,841 & 507,841 \\
\hline & & 1 & 682 & 30,695 & 30,695 & $1,018,785$ & $1,018,785$ \\
\hline & & 2 & 1,058 & 77,124 & 77,124 & $1,019,161$ & $1,019,161$ \\
\hline & & 3 & 10,854 & 208,008 & 208,008 & $1,028,957$ & $1,028,957$ \\
\hline & & 4 & 1,366 & 34,002 & 34,002 & $1,019,469$ & $1,019,469$ \\
\hline & & 5 & 7,047 & 243,101 & 243,101 & $1,025,150$ & $1,025,150$ \\
\hline & & Other & $1,782,550$ & $6,803,567$ & $6,803,567$ & $1,782,550$ & $1,782,550$ \\
\hline & & Total & $1,808,387$ & $7,401,914$ & $7,401,914$ & $7,401,914$ & $7,401,914$ \\
\hline & \multirow[t]{8}{*}{ Students in schools } & CBD & 1,087 & 1,219 & 1,219 & 341,717 & 341,717 \\
\hline & & 1 & 4,646 & 209,105 & 209,105 & 695,367 & 695,367 \\
\hline & & 2 & 429 & 31,272 & 31,272 & 691,150 & 691,150 \\
\hline & & 3 & 1,286 & 24,645 & 24,645 & 692,007 & 692,007 \\
\hline & & 4 & 1,708 & 42,515 & 42,515 & 692,429 & 692,429 \\
\hline & & 5 & 3,381 & 30,274 & 30,274 & 694,102 & 694,102 \\
\hline & & Other & $1,239,874$ & $4,707,615$ & $4,707,615$ & $1,239,874$ & $1,239,874$ \\
\hline & & Total & $1,252,411$ & $5,046,646$ & $5,046,646$ & $5,046,646$ & $5,046,646$ \\
\hline & \multirow[t]{8}{*}{ No. of retail shops } & CBD & 378 & 424 & 424 & 19,125 & 19,125 \\
\hline & & 1 & 61 & 2,745 & 2,745 & 38,058 & 38,058 \\
\hline & & 2 & 21 & 1,531 & 1,531 & 38,018 & 38,018 \\
\hline & & 3 & 65 & 1,246 & 1,246 & 38,062 & 38,062 \\
\hline & & 4 & 17 & 423 & 423 & 38,014 & 38,014 \\
\hline & & 5 & 217 & 7,943 & 7,943 & 38,214 & 38,214 \\
\hline & & Other & 66,561 & 261,739 & 261,739 & 66,561 & 66,561 \\
\hline & & Total & 67,320 & 276,051 & 276,051 & 276,051 & 276,051 \\
\hline
\end{tabular}

Italics indicate significant change to Scenario 0 
Table 4 The distribution of residential and activities into six centres by different scenarios in Melbourne

\begin{tabular}{|c|c|c|c|c|c|c|c|}
\hline Factors & Variable & Centre & 2008 & 2030 (Scenario 0) & Scenario 12030 & Scenario 22030 & Scenario 32030 \\
\hline \multirow[t]{24}{*}{ Residential } & \multirow[t]{8}{*}{ Households } & CBD & 9,936 & 12,859 & 54,090 & 12,859 & 54,090 \\
\hline & & 1 & 5,862 & 7,586 & 114,775 & 7,586 & 114,775 \\
\hline & & 2 & 3,154 & 5,821 & 112,067 & 5,821 & 112,067 \\
\hline & & 3 & 10,627 & 13,754 & 119,541 & 13,754 & 119,541 \\
\hline & & 4 & 15,455 & 20,002 & 124,369 & 20,002 & 124,369 \\
\hline & & 5 & 24,484 & 57,460 & 133,397 & 57,460 & 133,397 \\
\hline & & Other & $1,357,873$ & $1,898,631$ & $1,357,874$ & $1,898,631$ & $1,357,874$ \\
\hline & & Total & $1,427,391$ & $2,016,113$ & $2,016,113$ & $2,016,113$ & $2,016,113$ \\
\hline & \multirow[t]{8}{*}{ Workers } & CBD & 10,818 & 14,001 & 67,228 & 14,001 & 67,228 \\
\hline & & 1 & 6,517 & 8,434 & 145,661 & 8,434 & 145,661 \\
\hline & & 2 & 2,367 & 4,368 & 141,511 & 4,368 & 141,511 \\
\hline & & 3 & 12,845 & 16,625 & 151,990 & 16,625 & 151,990 \\
\hline & & 4 & 19,595 & 25,360 & 158,740 & 25,360 & 158,740 \\
\hline & & 5 & 27,477 & 64,486 & 166,622 & 64,486 & 166,622 \\
\hline & & Other & $1,767,762$ & $2,466,240$ & $1,767,762$ & $2,466,240$ & $1,767,762$ \\
\hline & & Total & $1,847,381$ & $2,599,514$ & $2,599,514$ & $2,599,514$ & $2,599,514$ \\
\hline & \multirow[t]{8}{*}{ Student in residences } & CBD & 947 & 1,226 & 26,449 & 1,226 & 26,449 \\
\hline & & 1 & 2,033 & 2,631 & 65,548 & 2,631 & 65,548 \\
\hline & & 2 & 2,651 & 4,893 & 65,572 & 4,893 & 65,572 \\
\hline & & 3 & 4,851 & 6,278 & 67,768 & 6,278 & 67,768 \\
\hline & & 4 & 7,778 & 10,067 & 70,694 & 10,067 & 70,694 \\
\hline & & 5 & 12,045 & 28,268 & 74,964 & 28,268 & 74,964 \\
\hline & & Other & $764,020.4$ & $1,081,081.2$ & $763,449.2$ & $1,081,081.2$ & $763,449.2$ \\
\hline & & Total & $794,325.4$ & $1,134,444.2$ & $1,134,444.2$ & $1,134,444.2$ & $1,134,444.2$ \\
\hline \multirow[t]{24}{*}{ Activities } & \multirow[t]{8}{*}{ Jobs } & CBD & 219,548 & 280,283 & 280,283 & 277,229 & 277,229 \\
\hline & & 1 & 13,637 & 18,354 & 18,354 & 160,739 & 160,739 \\
\hline & & 2 & 8,249 & 13,008 & 13,008 & 150,662 & 150,662 \\
\hline & & 3 & 20,333 & 26,150 & 26,150 & 162,714 & 162,714 \\
\hline & & 4 & 21,409 & 27,534 & 27,534 & 163,781 & 163,781 \\
\hline & & 5 & 23,832 & 44,978 & 44,978 & 166,234 & 166,234 \\
\hline & & Other & $1,548,321$ & $2,214,875$ & $2,214,875$ & $1,543,823$ & $1,543,823$ \\
\hline & & Total & $1,855,329$ & $2,625,182$ & $2,625,182$ & $2,625,182$ & $2,625,182$ \\
\hline & \multirow[t]{8}{*}{ Student in school } & $\mathrm{CBD}$ & 63,056 & 81,610 & 81,610 & 96,218 & 96,218 \\
\hline & & 1 & 20,536 & 26,579 & 26,579 & 108,510 & 108,510 \\
\hline & & 2 & 20,396 & 37,645 & 37,645 & 102,362 & 102,362 \\
\hline & & 3 & 15,984 & 20,687 & 20,687 & 97,909 & 97,909 \\
\hline & & 4 & 10,534 & 13,633 & 13,633 & 92,449 & 92,449 \\
\hline & & 5 & 30,472 & 71,514 & 71,514 & 112,424 & 112,424 \\
\hline & & Other & 943,266 & $1,295,707$ & $1,295,707$ & 937,503 & 937,503 \\
\hline & & Total & $1,104,244$ & $1,547,375$ & $1,547,375$ & $1,547,375$ & $1,547,375$ \\
\hline & \multirow[t]{8}{*}{ No. of retail shops } & CBD & 15,607 & 20,199 & 20,199 & 23,407 & 23,407 \\
\hline & & 1 & 1,822 & 2,358 & 2,358 & 21,611 & 21,611 \\
\hline & & 2 & 1,468 & 2,709 & 2,709 & 20,724 & 20,724 \\
\hline & & 3 & 2,340 & 3,028 & 3,028 & 21,592 & 21,592 \\
\hline & & 4 & 5,327 & 6,894 & 6,894 & 24,578 & 24,578 \\
\hline & & 5 & 6,215 & 14,587 & 14,587 & 25,470 & 25,470 \\
\hline & & Other & 229,663 & 316,760 & 316,760 & 229,153 & 229,153 \\
\hline & & Total & 262,442 & 366,535 & 366,535 & 366,535 & 366,535 \\
\hline
\end{tabular}

Italics indicate significant change to Scenario 0 
Table 5 Comparison of trip by modes between baseline 2030 and polycentric scenarios in Melbourne

\begin{tabular}{lccc}
\hline & $\begin{array}{l}\text { S1 } \\
\text { Change } \\
\text { \% vs. S0 }\end{array}$ & $\begin{array}{l}\text { S2 } \\
\text { Change } \\
\text { \% vs S0 }\end{array}$ & $\begin{array}{l}\text { S3 } \\
\text { Change } \\
\text { \% vs S0 }\end{array}$ \\
\hline HBW & & & \\
Car trip & -1.23 & 2.34 & -0.71 \\
PT trip & 1.91 & -7.71 & -6.19 \\
Walk trip & 17.93 & -5.09 & 59.24 \\
NHBW & & & \\
Car trip & -2.85 & -0.13 & -4.42 \\
PT trip & 6.37 & -0.21 & 5.80 \\
Walk trip & 6.86 & 1.26 & 15.60 \\
\hline
\end{tabular}

\subsection{Mode share}

\subsubsection{HBW purpose}

In Melbourne, car mode share declined in scenarios 1 and 3 , compared to the scenario 0 . However, scenario 2 had a higher rate of increase compared to all scenarios. PT share decreased in scenarios 2 and 3; however, PT share of scenario 1 increased compared to scenario 0. Walk trip increased in scenarios 1 and 3; however, scenario 2 was similar to scenario 0 (Table 7).

In Riyadh, all scenarios resulted in a slight decrease in car mode share. PT mode increased in all scenarios. Walk mode share increased in all scenarios, and scenario 3 had the highest increase (Table 8).

\subsubsection{NHBW purpose}

In Melbourne, car trip share declined in all scenarios compared to baseline year 2030. Scenario 3 had a larger decrease compared to scenarios 1 and 2. PT mode share increased in all scenarios. Also, the walk trip share increased in all scenarios compared to scenario 0 . Scenario 3 PT mode share was higher than that of scenarios 1 and 2.

Riyadh's result in mode share was similar to Melbourne's in terms of the decline in car mode share and increase in walk share. However, the PT share increased in scenario 1 and declined to a degree in scenario 3 . In scenario 2 there was no change compared to scenario 0 .

\subsection{Trip distance}

Table 1 shows the comparative analysis of trip distance between scenarios by HBW and NHBW purposes in both Melbourne and Riyadh.
Table 6 Comparison of trip by modes between baseline 2030 and polycentric scenarios in Riyadh

\begin{tabular}{lllr}
\hline & $\begin{array}{l}\text { S1 } \\
\text { Change } \\
\text { \% vs. S0 }\end{array}$ & $\begin{array}{l}\text { S2 } \\
\text { Change } \\
\text { \% vs S0 }\end{array}$ & $\begin{array}{l}\text { S3 } \\
\text { Change } \\
\text { \% vs S0 }\end{array}$ \\
\hline HBW & & & \\
Car trip & -7.83 & -3.35 & -20.32 \\
PT trip & 12.35 & 5.63 & 9.98 \\
Walk trip & 29.55 & 19.17 & 89.05 \\
NHBW & & & \\
Car trip & -3.04 & -5.01 & -16.25 \\
PT trip & 4.02 & -0.13 & -1.07 \\
Walk trip & 10.28 & 59.52 & 63.03 \\
\hline
\end{tabular}

\subsubsection{HBW purpose}

In the case of Melbourne, there was a reduction in car and PT trip distance for scenarios 1, 2 and 3. There was an increase in walk trips distance (Table 9).

For Riyadh, there was a decrease in trip distance by car, but there was an increase in trip distance by PT and walk (Table 10).

\subsubsection{NHBW purpose}

Similar to HBW, there was a reduction in car and PT trip distance for scenarios 1,2 and 3 there was an increase in walk trips distance in the case of Melbourne (Table 9).

For Riyadh, there was decrease in trip distance by car, but there was an increase in trip distance by PT and walk for scenarios 1 and 2. In the case of scenario 3, there was a decrease in trips distance for all modes (car, PT and walk) (Table 10).

\subsection{Travel time}

This section will display the trip time based on the different scenarios in both Riyadh and Melbourne for HBW and NHBW trip purpose.

\subsubsection{HBW purpose}

Table 11 shows that travel time by car has declined in all scenarios except scenario 2 for HBW purpose, compared to scenario 0. PT travel time decreased in all scenarios. Walk travel time increased in all scenarios.

In the case of Riyadh, car travel time decreased in all scenarios, particularly scenario 3 . PT travel time increased in scenario 1 and 2, but decreased in scenario 3. Walk travel time increased in all three scenarios. 
Table 7 Comparison of mode shares for baseline 2030 and polycentric scenarios in Melbourne

\begin{tabular}{|c|c|c|c|c|c|}
\hline & $2008(\%)$ & Scenario $0(\%)$ & Scenario $1(\%)$ & Scenario $2(\%)$ & Scenario $3(\%)$ \\
\hline \multicolumn{6}{|l|}{ HBW } \\
\hline Car share & 84.0 & 74.2 & 73.5 & 76.0 & 73.8 \\
\hline PT share & 14.8 & 24.5 & 25.0 & 22.8 & 23.1 \\
\hline Walk share & 1.3 & 1.2 & 1.5 & 1.2 & 3.0 \\
\hline \multicolumn{6}{|l|}{ NHBW } \\
\hline Car share & 81.0 & 71.9 & 69.9 & 71.8 & 68.8 \\
\hline PT share & 9.6 & 17.5 & 18.7 & 17.5 & 18.6 \\
\hline Walk share & 9.4 & 10.6 & 11.4 & 10.8 & 12.6 \\
\hline
\end{tabular}

Table 8 Comparison of mode shares for baseline 2030 and polycentric scenarios in Riyadh

\begin{tabular}{|c|c|c|c|c|c|}
\hline & $2008(\%)$ & Scenario $0(\%)$ & Scenario $1(\%)$ & Scenario $2(\%)$ & Scenario $3(\%)$ \\
\hline \multicolumn{6}{|l|}{ HBW } \\
\hline Car share & 99.3 & 67.4 & 62.6 & 65.3 & 56.1 \\
\hline PT share & - & 31.6 & 36.1 & 33.5 & 35.2 \\
\hline Walk share & 0.7 & 1.0 & 1.4 & 1.2 & 8.8 \\
\hline \multicolumn{6}{|l|}{ NHBW } \\
\hline Car share & 97.1 & 64.0 & 62.1 & 60.8 & 55.1 \\
\hline PT share & - & 30.6 & 31.9 & 30.6 & 30.3 \\
\hline Walk share & 2.9 & 5.4 & 6.0 & 8.6 & 14.5 \\
\hline
\end{tabular}

Table 9 Comparison of transport performance between baseline 2030 and polycentric scenarios in Melbourne

\begin{tabular}{llll}
\hline & S1 & S2 & S3 \\
& Change \% vs. S0 & Change \% vs S0 & Change \% vs S0 \\
\hline HBW & & & \\
Car PKT & -5.56 & -1.41 & -12.69 \\
PT PKT & -5.93 & -13.44 & -23.54 \\
Walk & 24.24 & 4.37 & 56.65 \\
PKT & & & \\
NHBW & & & -14.40 \\
Car PKT & -8.61 & -1.35 & -4.55 \\
PT PKT & -0.62 & -1.01 & 29.87 \\
Walk & 22.48 & 4.91 & \\
PKT & & & \\
\hline
\end{tabular}

\subsubsection{NHBW purpose}

In Melbourne, car travel time declined in all scenarios compared to scenario 0. PT travel time also decreased in all scenarios. Walk travel time increased in all three scenarios.

In Riyadh, Table 12 shows that car travel time decreased in all scenarios, particularly scenario 3. PT travel time changed slightly in scenarios 1 and 2 but decreased notably in scenario 3 . Walk travel time increased in scenarios 1 and 2, but decreased in scenario 3 .
Table 10 Comparison of transport performance between baseline 2030 and polycentric scenarios in Riyadh

\begin{tabular}{cccc}
\hline & $\begin{array}{l}\text { S1 } \\
\text { Change \% vs. S0 }\end{array}$ & $\begin{array}{l}\text { S2 } \\
\text { Change \% vs S0 }\end{array}$ & $\begin{array}{l}\text { S3 } \\
\text { Change \% vs S0 }\end{array}$ \\
\hline HBW & & & \\
Car PKT & -6.19 & -1.60 & -27.75 \\
PT PKT & 10.72 & 12.76 & 4.07 \\
Walk & 26.07 & 5.07 & 83.46 \\
PKT & & & \\
NHBW & & & -39.44 \\
Car PKT & -2.22 & -3.27 & -11.52 \\
PT PKT & 4.26 & 7.96 & -27.02 \\
Walk & 1.37 & 10.43 & \\
PKT & & & \\
\hline
\end{tabular}

This means that all services such as school, medical and retail lay close together, which assisted in reducing PT trip time. Walk trip time improved, particularly in scenario 3. This confirmed our expectation explained above, which is that self-containment leads to increasing walk trip. In Riyadh, car trip time declined in all scenarios; however, scenario 3 had a higher rate of decline in car trip time compared to scenarios 1 and 2. Also, this means that the provision of services may have helped in the reduction of car trip time. PT trip time fell in scenarios 2 and 3. The latter had a higher rate of reduction due to the 
Table 11 Comparison of transport performance by hours between baseline 2030 and polycentric scenarios in Melbourne

\begin{tabular}{cccl}
\hline & $\begin{array}{l}\text { S1 } \\
\text { Change \% vs. S0 }\end{array}$ & $\begin{array}{l}\text { S2 } \\
\text { Change \% vs S0 }\end{array}$ & $\begin{array}{l}\text { S3 } \\
\text { Change \% vs S0 }\end{array}$ \\
\hline HBW & & & \\
Car PHT & -3.24 & 0.91 & -5.37 \\
PT PHT & -2.22 & -3.88 & -6.95 \\
Walk & 0.11 & 0.02 & 0.50 \\
PHT & & & \\
NHBW & & & -5.86 \\
Car PHT & -3.58 & -0.16 & -1.05 \\
PT PHT & -0.21 & -0.44 & 1.42 \\
Walk & 0.94 & 0.16 & \\
PHT & & & \\
\hline
\end{tabular}

Table 12 Comparison of transport performance by hours between baseline 2030 and polycentric scenarios in Riyadh

\begin{tabular}{llll}
\hline & $\begin{array}{l}\text { S1 } \\
\text { Change \% vs. S0 }\end{array}$ & $\begin{array}{l}\text { S2 } \\
\text { Change \% vs S0 }\end{array}$ & $\begin{array}{l}\text { S3 } \\
\text { Change \% vs S0 }\end{array}$ \\
\hline HBW & & & \\
Car PHT & -5.72 & -1.27 & -20.15 \\
PT PHT & 2.36 & 1.14 & -1.87 \\
Walk & 0.35 & 0.05 & 5.72 \\
PHT & & & \\
NHBW & & & -26.23 \\
Car PHT & -1.79 & -2.60 & -7.30 \\
PT PHT & 0.59 & -0.83 & -2.39 \\
Walk & 0.12 & 0.99 & \\
PHT & & & \\
\hline
\end{tabular}

concentration of all services near the residential structure. Walk trip time would increase slightly in scenarios 1 and 2, at 0.12 and 0.99 , respectively. However, scenario 3 fell slightly at -2.39 . This means that some services in and around suburban activity centres mean that many more people will be able to walk less than $2 \mathrm{~km}$.

\section{Conclusion}

In this paper, we have reported on comparative analysis through modelling that investigated the shift from monocentric to polycentric structure, and from private mode- to PT mode-oriented city for Riyadh and Melbourne. The results indicate that planned and concentrated employment and population in key activity centres may deliver significant benefits to reducing car trip distance. The findings of the combined and coordinated redistribution of activity and residences would achieve the best possible transport outcome, with regards to reducing car trips, car mode share, car travel distance and car travel. It also reduced travel consumption in general, including PT travel. It also promoted walk trips.

The finding of the study pointed that combination and coordination of activity and residences redistribution into polycentric structure for Melbourne and Riyadh will bring about significant benefits and will play a key role in achieving a more sustainable transport outcome.

It is recommended that urban restructure polices should focus on both activity and residence re-alignment.

This study did not include network assignment. Further research is needed to examine in detail the impact of urban restructure with consideration to the capacity of the actual network.

Open Access This article is distributed under the terms of the Creative Commons Attribution License which permits any use, distribution, and reproduction in any medium, provided the original author(s) and the source are credited.

\section{References}

1. Weisbrod G, Vary D, Treyz G (2003) Measuring economic costs of urban traffic congestion to business. Transp Res Record 1839(1):98-106

2. Burke M, Dodson J, and Gleeson B (2010) Employment decentralisation in South East Queensland: scoping the transport impacts. Research paper, 2010. 29

3. Anas A, Arnott R, Small KA (1998) Urban spatial structure. J Econ Lit 36(3):1426-1464

4. McMillen DP, McDonald JF (1998) Population density in suburban Chicago: a bid-rent approach. Urban Stud 35(7):1119-1130

5. Cervero R (2004) Transit-oriented development in the United States: Experiences, challenges, and prospects. Transp Res Board 102:3-12

6. DPCD (2007) Melbourne 2030 Audit analysis of progress and findings from the 2006 Census Melbourne. Government of Victoria. Department of Planning and Community Development, 2007

7. DPCD (2011) Central activities areas. Government of Victoria. Department of Planning and Community Development, 2011

8. ADA (2004) Masterplan phase 2. High commission for the development of Riyadh, Arriyadh Development Authority 2004

9. Aguiléra A, Wenglenski S, Proulhac L (2009) Employment suburbanisation, reverse commuting and travel behaviour by residents of the central city in the Paris metropolitan area. Transp Res Part A 43(7):685-691

10. Mees P, O'Connell G, Stone J (2008) Travel to work in Australian capital cities, 1976-2006. Urban Policy Res 26:363-378

11. DPCD (2008) Melbourne 2030 a Planning Update: Melbourne @5 Million Melbourne, Victoria Government. Department of Transport, Victoria, Melbourne, 2008

12. de Dios Ortúzar J (2001) Modelling transport. Wiley, Chichester 